\title{
Experiment of Water Phase-change Cycles and Analysis of Damage Characteristics for Argillaceous Dolomite
}

\author{
Jian-Hua DENG ${ }^{a}$, Fang YU ${ }^{b}$, Gui-Lin WANG ${ }^{c}$, Yong-Yi LI ${ }^{d}$ \\ School of Civil Engineering, Guizhou University, Guiyang, Guizhou, 550003, China \\ ajhdengsjtu@qq.com, b347485363@qq.com, ${ }^{\text {c904009054@qq.com, }{ }^{d} 1326345628 @ q q . c o m}$
} Keywords: Argillaceous Dolomite, Water Phase-change Cycle, Supersonic Detection, Damage
Characteristics.

\begin{abstract}
For the purpose of research on behavior of argillaceous dolomite suffering from extreme weather impacts in Guizhou region, Study the behavior of the physical properties of rock samples after the water phase transition effect. By wet and dry cycle test, freeze-thaw cycle test, wet freeze-thaw cycle test on rock samples, studying the longitudinal wave velocity, the macro scale and quality parameters of the rock samples after each cycle, while observing the appearance of the rock sample characteristics, and explaining the reason for the parameters change of the rocks macroscopic properties from the microscopic. The results show that in the water phase-change cycle (wet and dry cycle test, freeze-thaw cycle test, wet freeze-thaw cycle test) process, the rock sample degradation forms performance for chipping, flaking mode, longitudinal wave velocity decreases obviously, and Longitudinal wave velocity decreased respectively by $18.01 \%, 14.88 \%$ and $17.05 \%$ on average, while mass has a small increase, maximum change rate of $0.5 \%$. Macroscopic properties of the rock are significantly affected by water phase-change cycle.
\end{abstract}

\section{Introduction}

By cryogenic freezing weather, The roadbed, bridges, tunnels, slope and other projects on the highways is located in the Yunnan-Guizhou Plateau of Guizhou Province, vulnerable to the effects of weather especially extreme weather, frequently prone to geological disasters. In order to achieve the purpose of disaster prevention and mitigation, the need for rock performance characteristics in-depth research under extreme climatic conditions, argillaceous dolomite widely distributed in the Guizhou region and in the area of common rocks as the research object, with regional representation. Rapid phase transitions indoor cycling test for understanding the damage, behavioral characteristics of argillaceous dolomite in extreme climatic environments are one of the most direct and effective disaster prevention and mitigation measures.

Currently, the water-rock interaction is one of the topics at the forefront of Geotechnical engineering [1-7], the water in single-phase (liquid) state impact study of rock material softening of the more common [7-14], liquid-solid water phase transition (freeze-thaw cycles) on the rocks made useful exploration. Houri $\mathrm{M}$ and Morihiro H.[15] by simplifying the model from a microscopic point of view of the void damage mechanism of rock and other porous material, material under freezing and thawing cycles; Ruize V.G [16], Yang gengshe [17], Zhang SJ [18], etc., By using the CT scanning technology, the freeze-thaw damage process of sandstone, shale, tunnel surrounding rock were meso research; He guoliang[19],Lin zhanju[20], etc., used non-metallic ultrasound to marble, sandstone, mudstone, clastic that suffered from freeze-thaw cycle for ultrasonic longitudinal wave non-destructive testing; Mutlutürk $M$ et al [21] used a mathematical model describing the marble, limestone, cave rock (travertine) in the freeze-thaw cycle, such as integrity; Kubicar L et al[22] used a transient pulse method for measuring the thermal physical parameters under conditions of freeze-thaw cycles of sandstone, and given guidance on engineering practice; Demirdag S[23] travertine (tufa) in the freeze-thaw cycles and thermal shock tests carried out load strength parameters; Zhang huimei and Yang gengshe[23] through thaw mechanics of sandstone and shale saturated, studied the effects of lithology, freeze-thaw cycles and other damage to the mechanical properties of the rock, and used phenomenological damage mechanics and 
non-equilibrium statistical concepts and methods to establish the damage evolution equation of freeze-thaw rocks.

As can be seen, the present study relates only to the portion of the water phase transition, and only some of the typical rock types studied, research methods are simpler, no water circulation phase change impact studies on rock properties.

Aim to the research of argillaceous dolomite, Guo Jianqiang [12] studied the influence of moisture changes in the weathering properties of the rock. Huang yanseng et al [13] studied the influence of moisture changes in the mechanical properties of the rock. However, the study of water phase change problem about mud dolomite is currently no reports, with the help of ultrasonic detector, vernier caliper, quality, balance etc. Laboratory instruments, the paper conducted a nondestructive test on the macroscopic properties of argillaceous dolomite in water phase transformation conditions, and explained the why the macroscopic characteristic parameters of the rocks show changes in the environment of water phase transformation from the microscope.

Through recognizing the damage mechanism of argillaceous dolomite qualitative change in the water phase change environment, it will Plays a role in extreme climate conditions engineering construction of the rock.

\section{Tests}

\section{Sample Preparation}

A test used argillaceous dolomite stone from a rock slope in the Guizhou site, rock sample is $50 \mathrm{~mm} \times 100 \mathrm{~mm}$ (diameter $\times$ height) cylinder [25]. To reduce the discrete experimental data, will make the difference in the appearance of the rock sample to eliminate large, then the remaining sample ultrasonic velocity measurement, according to the principle of velocity similar to elect a total of 17 sample groups, eight samples in each group, a total of 136, shown in Figure 1.

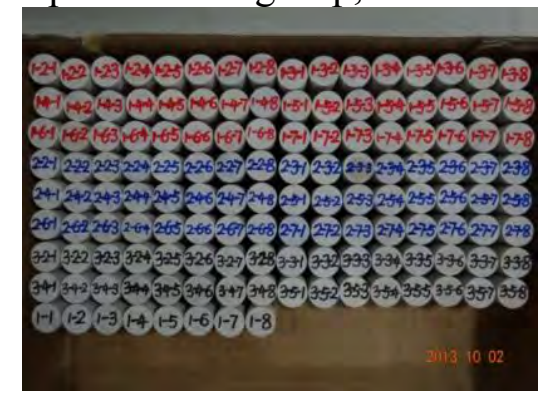

Fig. 1 Specimens of Argillaceous Dolomite

\section{Instrument}

The main instrument used in the experiments and the parameters is as follows:

(1)RongSheng BCD-218C cryogenic CNC incubators is used to freeze rock samples, volume is $218 \mathrm{~L}$, the lowest temperature is $-22^{\circ} \mathrm{C}$, precision control is $1^{\circ} \mathrm{C}$.

(2)Electric oven is a Ltd. 101-2 type electric oven thermostat blast made by Shanghai Feiyu Laboratory Equipment Co, maximum temperature is up to $300{ }^{\circ} \mathrm{C}$.

(3)Size measurement is comprised by use calipers whose precision $0.02 \mathrm{~mm}$, range of $150 \mathrm{~mm}$.

(4)Quality measurement is comprised of an electronic balance whose precision $0.01 \mathrm{~g}$, range is $2 \mathrm{~kg}$ of APT457A.

(5)Ultrasonic testing is comprised by nonmetallic ultrasonic detector made by Wuhan rock sea using company RS-ST01C, the measurement accuracy is $0.1 \mu \mathrm{s}$.

\section{Methods}

(1)All rock samples were initially making good measure, including the size, quality, longitudinal wave velocity. 
(2)Place all the sample in $105 \sim 110{ }^{\circ} \mathrm{C}$ baking in the oven for $24 \mathrm{~h}$, and then put it in the dryer to cool to room temperature, scale sample drying quality and ultrasonic longitudinal wave nondestructive testing was carried out on the sample.

(3)Wet and dry cycle test: the saturated sample, placed in the oven at a temperature of $105{ }^{\circ} \mathrm{C} \pm$ $2{ }^{\circ} \mathrm{C}$ drying $12 \mathrm{~h}$, then remove to soak in the sink, the water temperature is maintained at $20{ }^{\circ} \mathrm{C} \pm$ $2{ }^{\circ} \mathrm{C}$, water $12 \mathrm{~h}$, is a sub-wet and dry cycle, that cycle of each wet-dry cycle of $24 \mathrm{~h}$, a total of 30 cycles.

(4)Freeze-thaw cycle test: the first group of 8 to 13 samples after saturation, placed in the freezer at a temperature of $-20{ }^{\circ} \mathrm{C} \pm 2{ }^{\circ} \mathrm{C}$ frozen $12 \mathrm{~h}$, then remove to soak in the sink, the water temperature is maintained at $20{ }^{\circ} \mathrm{C} \pm 2{ }^{\circ} \mathrm{C}$, dissolution $12 \mathrm{~h}$, is a freeze-thaw cycles, that is, each cycle of freeze-thaw cycle was $24 \mathrm{~h}$, a total of 30 cycles.

(5)The last set of tracking test specimens after different cycle's volume, mass, longitudinal wave velocity parameters and observe the specimen apparent changes.

\section{Results and Analysis}

\section{Initial Rock Physical Properties}

By experimenting, some of the physical parameter's average of the initial acquisition of argillaceous dolomite is obtained and shown in Table 1.

Tab. 1 Physical Parameters of Argillaceous Dolomite

\begin{tabular}{llllccc}
\hline Lithology & $\begin{array}{l}\text { Dry } \\
\text { density } \\
/ \mathrm{g} \mathrm{C} \mathrm{Cm}^{-3}\end{array}$ & $\begin{array}{c}\text { Drying } \\
\text { velocity } \\
/ \mathrm{M.} \mathrm{S}^{-1}\end{array}$ & $\begin{array}{c}\text { Saturated } \\
\text { density } \\
/ \mathrm{g} . ~ C m^{-3}\end{array}$ & $\begin{array}{c}\text { Saturated } \\
\text { moisture } \\
\text { content } / \%\end{array}$ & $\begin{array}{c}\text { Saturated } \\
\text { velocity of } \\
\text { sound } / \mathrm{m} \mathrm{S}^{-1}\end{array}$ & Porosity $/ \%$ \\
\hline $\begin{array}{l}\text { Argillaceous } \\
\text { dolomite }\end{array}$ & 2.60 & 3688.91 & 2.65 & 1.98 & 3283.5 & 5.12 \\
\hline
\end{tabular}

Argillaceous dolomite is more than $50 \%$ of the fine particle size less than $0.0005 \mathrm{~mm}$ detrital material composed of dolomite and clay minerals, The main component based on $\mathrm{SiO} 2$,content is generally $50 \% \sim 70 \%$, The second is $\mathrm{Al} 2 \mathrm{O} 3$, the content is generally $15 \% \sim 20 \%$, and contains a small amount of $\mathrm{Fe} 2 \mathrm{O} 3, \mathrm{FeO}, \mathrm{CaO}$.

The main exterior color was gray (containing a small amount of dolomite particles), brown (the connotation of a small amount of $\mathrm{Fe} 2 \mathrm{O} 3, \mathrm{FeO}$ sake), absorbent strong, can be identified by 10 percent of dilute hydrochloric acid, which reacts with dilute hydrochloric acid rock is not blistering, or from the micro bubbles (containing a small amount of calcite), mainly distinguished from limestone.

After cooling the sample drying at room temperature when placed in water will soak whistling through rock sample velocity decreased after soaking. From Table 1, the rock samples from the dry state to the saturated state velocity reduced by $11 \%$, indicating a greater impact of muddy water sensitivity of dolomite rock, the rock properties of water.

\section{The Change of the Rock Appearance}

Figure 2 shows the argillaceous dolomite 6-5 samples were characterized by the appearance of the change process after freeze-thaw cycles of different photos. After 30 times freeze-thaw cycle, several kinds of typical damage sample as shown in figure 3.

A typical sample taken for analysis can be seen from Figure 2, when the sample 10 times to freezing and thawing cycles, the loose part of the surface of the particles of rock samples, and begin to appear visible initial crack, crack extension direction of the sample is substantially ring to crack length of about $4 \mathrm{~cm}$, width of about $0 \sim 1.5 \mathrm{~mm}$, increases the number of freeze-thaw, when the crack widened and gradually become evident to the 20th, there was greater macro-crack, crack length of about $7.5 \mathrm{~cm}$, a width of about $0 \sim 2 \mathrm{~mm}$, Further, then crack to 25 times, more than a single 
crack propagation of the crack by initially into cracks, are interwoven.

From the entire testing process, the initial crack appeared most concentrated sample at 5 to 7 cycles, the main direction of extension of the ring to crack distribution, but also to carry out the extension and oblique longitudinal distribution, shown in Figure 3, 5 to 12 times during the crack developed rapidly after the crack development tends to slow down, during 20 cycles, rock samples appear chipping, peeling, shown in Figure 3 samples 7-7, after 25 cycles, the sample disturbed easy to fall, and can be crumbled by hand.

By trial found argillaceous dolomite experience different injury after freeze-thaw cycle deterioration mode mainly for peeling mode, the damage deterioration process: water erosion surface of sample $\rightarrow$ particle part loose $\rightarrow$ microporosity increases $\rightarrow$ micro cracks initiation sample surface $\rightarrow$ surface appear weak layer, slice off the denudation $\rightarrow$ macroscopic crack appears, further softening the surface, loose $\rightarrow$ the massive spalling $\rightarrow$ water continues to penetrate to the interior $\rightarrow$ Rock deterioration continues to deepen.

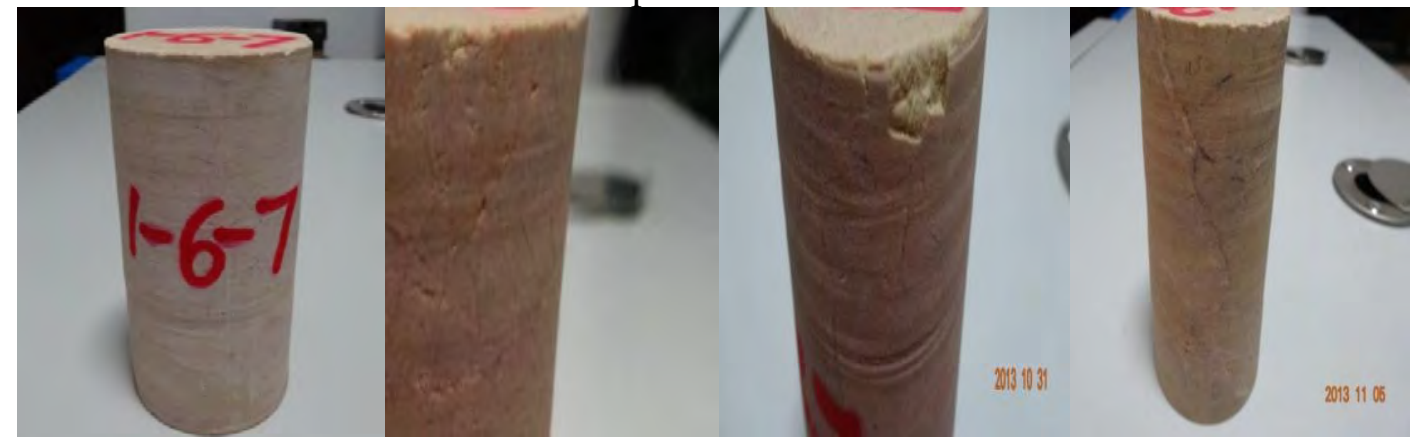

(a) 0 times wet and dry cycles (b) 10 times the wet and dry cycles (c) 20 times the wet and dry cycles (d) 25 times wet and dry cycles

Fig. 2 Appearance Features Pictures of the Argillaceous Dolomite after Different Freezing-thawing Cycles

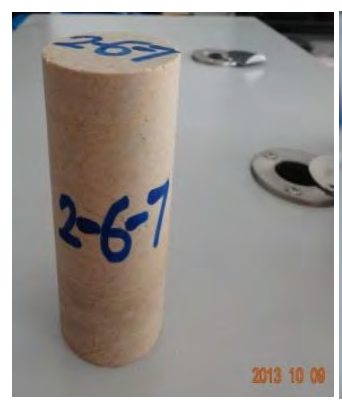

Visible cracks appear

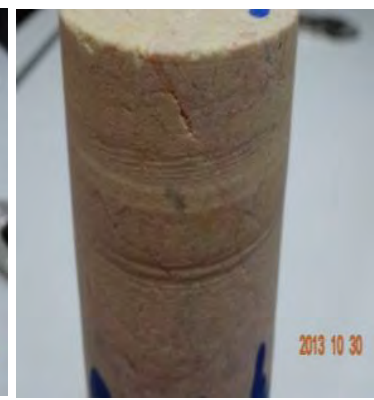

the crack expansion

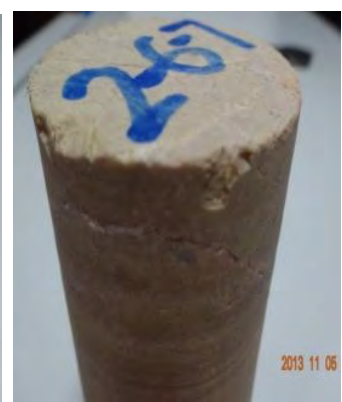

Surface circumferential crack

(a) 0 freeze-thaw cycles (b) 10 freeze-thaw cycles (c) 20 freeze-thaw cycles (d) 25 freeze-thaw cycles

Fig. 3 Appearance Features Pictures of the Argillaceous Dolomite after Different Freezing-thawing Cycle

\section{The Mass Change of the Rock}

The quality of the rate of change is an important parameter reflecting the rock after thawing response. Figure 4 shows the variation of different quality water phase change action under rocks. Map data in the table to the average of the sample is representative value.

From the water phase change process, the quality of the rock sample rate of change in $1 \sim 6 \sim 8$ cycles vary widely, between 0.1 to $0.43 \%$, and then slowed down, after 20 cycles stabilized. This is mainly due to the loss of the rock itself is a natural material, and the porosity is large, rock-like phase transitions in the early cycles under the action of the water damage is more serious (the appearance of damage seen statements from the front of the rock), water erosion and infiltration of the specimen where lead to the overall quality of the rock sample increased, at 8 to 20 cycles tends to slow the change in mass (mass change ratio of $0.4 \%$ to $0.5 \%$ ), the process tends to be more stable rock sample damage, after 20 cycles, the quality of the rate of change decreased slightly, mainly because some rock samples appear chipping and peeling late due. Quality is the result of changes in 
the sample of the solid material damage and freeze-thaw process of balancing the amount of moisture sucked badly.

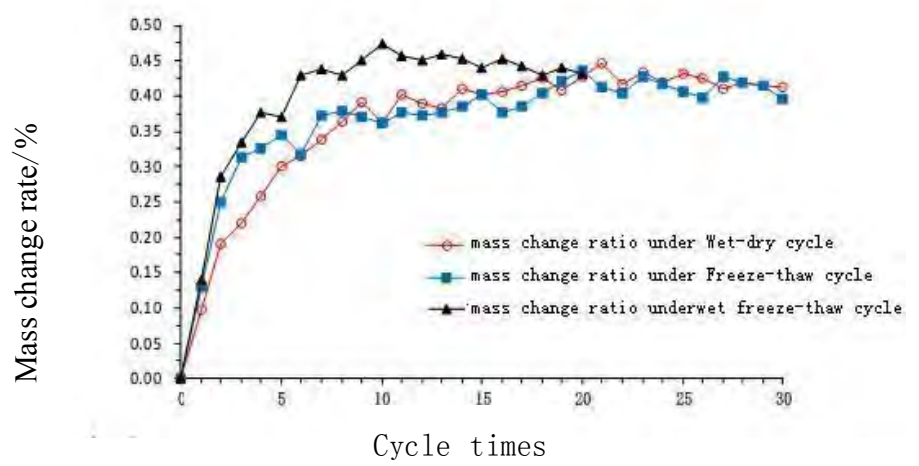

Fig. 4 Mass Changing Ratio of Rock Specimens Varying with Different Cycles

\section{The Volume Change of the Rock}

Fig. 5-7 are rocks in the dry and wet, freezing and thawing conditions change wet and dry conditions

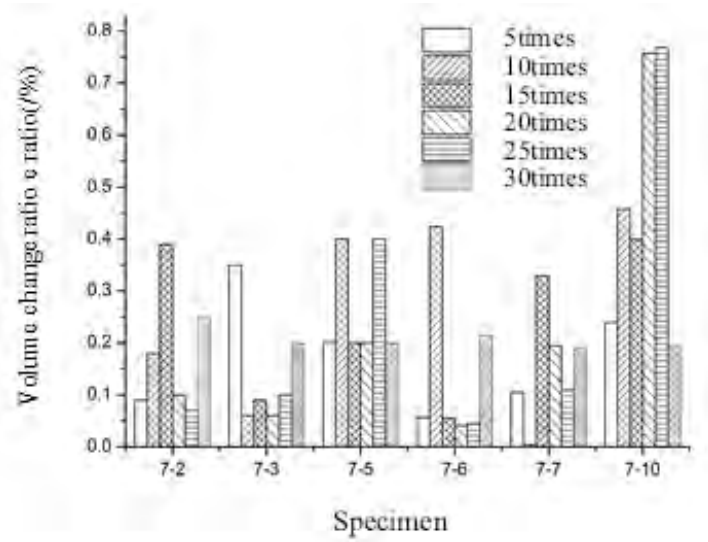

Fig. 5 Volume Changing Ratio of Rock Specimens Varying with Drying-wetting Cycles

As can be seen from Figure 5, the volume of the rock sample rate varies from $0.01 \%$ to $0.60 \%$, after the wet and dry cycle test, the rock sample volume did not change significantly, individual rock sample measurements unchanged.

\section{LWV (longitudinal wave velocity) Changes}

Continuous wave velocity and the degree of compaction and related solid rock, it is a measure of the rock alteration and destruction due to mechanical or thermodynamic method caused a more sensitive parameter, jointed rock degree of development, and Tim jointed thickness of the interlayer and other factors [26].

According to the following formula to calculate the rock freezing longitudinal wave velocity change:

$$
v=\frac{v_{\mathrm{fim}}-v_{\mathrm{p}}}{v_{\mathrm{s}}} \times 100 \%
$$

$v$-Rock thaw volume change rate $(\%)$, retained three significant figures,

$v_{\mathrm{p}}$-Thaw before saturating the specimen volume, $\mathrm{m} / \mathrm{s}$,

$v_{\text {fim }}$-After freezing and thawing of saturated specimen volume, $\mathrm{m} / \mathrm{s}$; 
$v_{\mathrm{s}}$-Test specimen volume before drying, $\mathrm{m} / \mathrm{s}$.

Figure 6 is a longitudinal wave velocity changes with the freeze-thaw cycles.

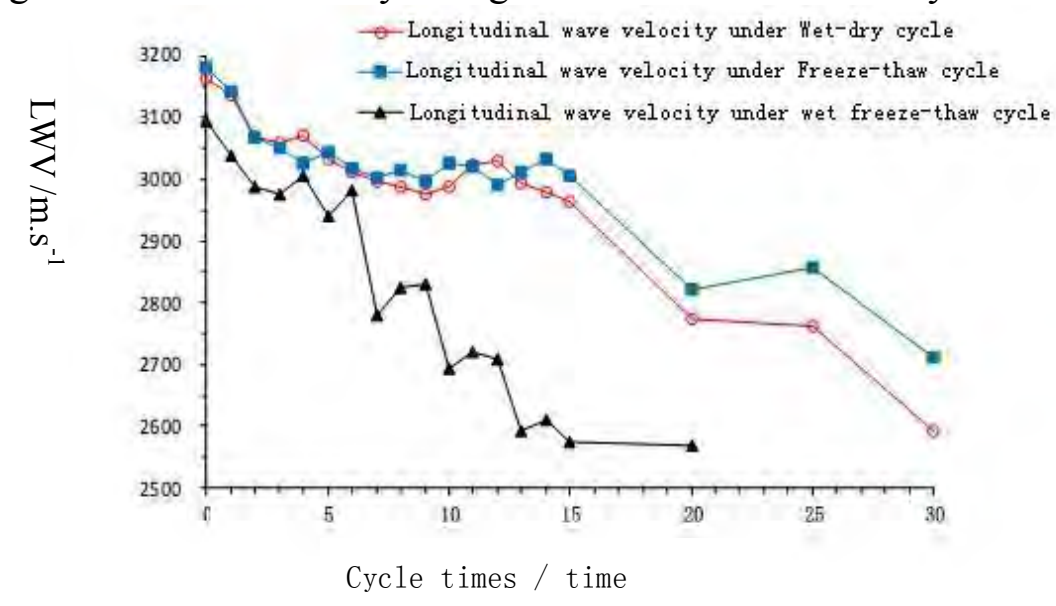

Fig. 6 Longitudinal Wave Velocity of Rock Specimens Varying with Different Cycles

As can be seen from Figure 8, after the wet and dry cycles, freeze-thaw cycles and wet freeze-thaw cycle test, the rock sample average longitudinal wave velocity has declined, the average velocity decreased by $18.01 \%, 14.88 \%$ and $17.05 \%$, indicating that the water phase changes cycle effects greater impact on the nature of the rock sample.

\section{Microscopic Interpretation for Macroscopic Properties Change of Argillaceous Dolomite after FTC (freezing-thawing cycles)}

Argillaceous dolomite particles mainly composed of dolomite, clay minerals, bound water composition, the presence of initial micro voids or micro cracks, containing free water or air, for the three-phase rock material, physical and thermal properties of the components are quite different. From Table 1, argillaceous dolomite saturated with water before freezing was $1.98 \%, 5.12 \%$ porosity, water absorption is strong, large porosity. Before water phase transition, three-phase equilibrium geometry and mechanics maintain the integrity and stability of the rock macro.

Once in the water phase change environment, rock ambient temperature and internal temperature changes, due to the different thermal properties of the rock physics of each substance, dolomite particles smaller volume contraction, large deformation of clay minerals, the rock will break the balance and stability of the initial state .Meanwhile phase change of water, the volume of water also changed, will further promote the balance of structural changes within the rock. When water in the liquid state, will dissolve soluble substances rocks, prompting changes in the structure of rock. Migration and infiltration of water will gradually fill voids or defects larger scale, in order to increase the quality of the performance of the macro, and the dissolution will weaken the structure, formation of voids and defects, resulting in cracks and will face off. Water is in the solid state, migration and infiltration of water, will gradually fill voids or defects larger scale, the same as the increase in macroeconomic performance on quality, but in the solid state, the volume of water increases, the surrounding rock will produce frost, because of uneven rock, making the water phase change in the environment of rock particles, deformation of the shift, when such a shift over the surrounding when the limit, even if the water from the solid state into the gaseous or liquid state, the deformation is irreversible, thus the formation of cracks or defects, make the rock particles in the water phase change environmental impact in a new geometric position to achieve the overall balance and stable state. Phase change in the water cycle, when such irreversible changes increase, or dissolved lead to an increase in the particle flow is the micro-defects or micro-cracks increased, resulting in the macro, rock-like surface cracks until shedding phenomenon in rock samples internal voids, resulting in longitudinal wave velocity decreases. Periodic phase change of water circulation, equivalent to fatigue effects, can cause damage to the rock constant deterioration of the internal structure, showing the changes in the macroeconomic characteristic parameters. 


\section{Conclusions}

(1)Phase change of water circulation can cause damage argillaceous dolomite continuous deterioration, Show various shapes of the cracking of the macro, its apparent damage degradation model characterized by scaling, flaking.

(2)Average sample quality increases, the maximum rate of $0.47 \%$, the quality of the change is a solid material sample loss and inhaled water component in the process of freezing and thawing poorly balanced result.

(3)The water volume of the phase change has little effect on the rock cycle, the volume change rate between $0.04 \%$ to $0.77 \%$ did not change significantly rock volume, the individual measurements in the sample did not change.

(4)Wet and dry cycles, freeze-thaw cycles and wet after freeze-thaw cycle test, the rock sample average longitudinal wave velocity has declined, the average velocity decreased by $18.01 \%, 14.88 \%$ and $17.05 \%$, indicating that the water phase transition effect on rock sample loop properties greater impact.

(5)Phase change affects water circulation, mainly reflected in the impact on the rock structure. When the water in the liquid state, it will dissolve away the rock or rock particles. When in solid, frost occurs, forming a tensile stress.

\section{Acknowledgement}

Foundation item: National Natural Science Foundation of China (51068003), Science and Technology Department Fund of Guizhou Province (Guizhou Branch of J word [2011] No. 2324)

\section{References}

[1]Belkhiri Lazhar,Mouni Lotfi,Tiri Ammar. Water-rock interaction and geochemistry of groundwater from the Ain Azeaquiter, Algeria [J]. Environmental Geochemistry and Health, 2009, 28 (10); 1995-2005.

[2]Abdelgawad M, Watanabe K,Takeuchi S. Water-rock interaction study on the occurrence of fluoride-rich groundwater at Miaunamiarea: area, Japan[J]. Environment Asia, 2009, 2; 20-29.

[3]LU Yingfa, LU Tao. Investigation on mechanical parameters of water-rock interaction[C]//Proc. 12th International Congress on Rock Mechanics of the International Society for Rock Mechanics. Philadelphia;Taylor and Francis Inc, 2012, 711-716.

[4]Mironenko M V, Zolotov M Y. Equilibrium-kinetic model of water-rock interaction [J]. Geochemistry International, 2012, 50(1); 1-7.

[5](PENG Shuguang, PEI Shicong. Experimental study of compression strength and micro-topography description index for groundwater saturated rock [J]. Journal of Experimental Mechanics, 2010, 25(3); 365-371. (In Chinese))

[6]DENG Jianhua. Study on the Water Damage Evolution Model of Gypsum Breccia and Its Mechanical Properties [D]. Shanghai; Shanghai Jiao Tong University, 2010.

[7]Liu Xinrong,Fu Yan,Zheng Yingren,et al. A review on deterioration of rock caused by water-rock interaction [J] Chinese Journal of Underground Space and Engineering, 2012, 8(1); 77-82. (In Chinese)

[8]Hawkins A B, McConnell B J. Sensitivity of sandstone strength and deformability to changes in moisture content[J]. Quarterly Journal of Engineering Geology, 1992, 25; 115-130.

[9]KANG Hongpu. Rock damage for water[J].Hydrogeology and Engineering Geology, 1994, 21(3); 39-41. (In Chinese) 
[10]CHEN Ganglin, ZHOU Rende. An experiment study concerning the macroscopic effect of water on the deformation and failure of loaded rocks[J]. Chinese Journal of Geophysics, 1991, 34(3); 335-342. (in Chinese)

[11]DENG Jianhua, HUANG Xingchun,PENG Jiebing,et al. Mechanical properties of Gypsum Breccia with different water contents[J]. Chinese Journal of Geotechnical Engineering, 2008, 30(8):1203-1207. (In Chinese)

[12]GUO Jianqiang. Experimental study on weathering characteristics with different moisture content of argillaceous dolomite [D]. Guiyang; Guizhou University, 2009. (In Chinese)

[13]HUANG Yansen, Deng jianhua, Zhong Shuhui,etal. Experimental Study on Mechanical Property of Argillaceous Dolomite with Different Moisture Content[J]. Chinese Journal of Underground Space and Engineering, 2014.04, 2(10):276-284. (In Chinese).

[14]Erguler Z A,Ulusay R. Water-induced variations in mechanical properties of clay-bearing rocks[J]. International Journal of Rock Mechanics and Mining Sciences, 2009, 46; 355-370.

[15]Hori M,Morihiro H. Micromechanical analysis of deterioration due to freezing and thawing in porous brittle materials[J]. International Journal of Rock Mechanics and Mining Sciences, 1998, $36(4) ; 511-522$.

[16]Ruize de Argandona V. G.,Rodriguez Rey A,Clorio C. Characterization by computed X-ray tomography of the evolution of the pore structure of a dolomite rock during freeze-thaw cyclic tests[J]. Phys. Chem. Earth, 1999, 7(24); 633-637.

[17]YANG Gengshe, PU Yibing, MA Wei. Discussion on the damage propagation for the rock under the frost and thaw condition frigid zone [J]. Journal of Experimental Mechanics, 2002, 17(2); 220-226. (In Chinese))

[18]Zhang S J, Lai Y M, Zhang X F,et al. Study on the damage propagation of surrounding rock from a cold-region tunnel under freeze-thaw cycle condition[J]. Tunnelling and Underground Space Technology, 2004, 19(3); 295-302.

[19](HE Guoliang, ZHANG Lei,WU Gang. Test study on physical characteristics of rock under freezing-thawing cycles [J]. Rock and Soil Mechanics, 2004, 25(2); 52-56. (In Chinese))

[20]LIN Zhanju, NIU Fujun, LIU Hua. Influences of freezing-thawing cycles on physic-mechanical properties of embankment revetments in permafrost regions[J]. Rock and Soil, 2011, 32(5); 1369-1376.(in Chinese))

[21]Mutlutürk M, Altindag R, Türk G. A decay function model for the integrity loss of rock when subjected to recurrent cycles of freezing-thawing and heating-cooling $[\mathrm{J}]$. International Journal of Rock Mechanics \& Mining Sciences, 2004, 41; 237-244.

[22]Kubicar L,Vretenar V, Bobac V,et al. Thermophysical analysis of sandstone by pulse transient method[J]. International Journal of Thermophysical, 2006, 27(1); 220-234.

[23]ZHANG Huimei, YANG Gengshe. Freeze-thaw cycling and mechanical experiment and damage propagation characteristics of rock[J]. Journal of China University of Mining and Technology, 2011, 40(1); 140-145 (in Chinese)

[24]Demirdag S. Effects of freezing-thawing and thermal shock cycles on physical and mechanical properties of filled and unfilled travertines[J].Construction and Building Materials, 2013, 47; 1395-1401.

[25]Yangtze River Scientific Research Institute, Changjiang Water Resources Commission. SL264-2001Specifications for rock tests in water conservancy and hydroelectric engineering[S]. Beijing; China Water Press, 2001. (In Chinese) 